\title{
What kind of trading drives return autocorrelation?
}

\author{
Chun-Kuei Hsieh and Shing-yang Hu* \\ Department of Finance, National Taiwan University
}

November 2008

This paper proposes new tests for the prediction of Llorente, Michaely, Saar, and Wang (2002) that information trading drives positive autocorrelation. Data from the Taiwan Stock Exchange is used to exploit the differences in the trading motivations of three groups of institutional investors. Consistent with the predictions, we find that heavy trading by foreigners and mutual funds will increase the autocorrelation particularly for large firms, and that heavy trading by dealers will not. We also find that the sell volume of mutual funds - short sales are disallowed by regulation - has significantly smaller effect on the autocorrelation of returns than buy volume. A portfolio strategy that exploits the observed autocorrelation pattern can generate a significantly positive daily return.

Keywords: information trading, allocation trading, return autocorrelation, short sale. JEL: G12, G15

We would like to thank participants of the $15^{\text {th }}$ Conference on the Theories and Practices of Securities and Financial Markets and two anonymous referees for their helpful suggestions Corresponding author: Shing-yang Hu, Department of Finance, National Taiwan University, Room 715, No. 85, Sec. 4, Roosevelt Road, Taipei, Taiwan 106. Telephone: +886-2-33661085; Fax: +886-2-23661299; E-mail address: syhu@ntu.edu.tw. 


\section{Introduction}

In securities markets, trading volume is highly publicized information. There exists a lengthy list of papers that examine the relationship between volume and the return process. ${ }^{1}$ Llorente, Michaely, Saar, and Wang (2002, LMSW hereafter) developed a model that examines how trading volume affects the autocorrelation of returns when investors may trade for an informational or hedging purpose. This paper builds on that literature and provides new tests for the LMSW model using data from the Taiwan Stock Exchange. The new tests are made possible because the data allows for the identification of two subgroups, namely, trading that is primarily information based and trading that is not.

LMSW's research revealed that when investors trade on private information, price changes are likely to continue. Given the existence of positive private information, informed investors will buy and drive up the price. However, when the information is not perfect, there will be only a partial price increase that will continue into the future. Therefore, returns are positively autocorrelated when investors trade on private information.

When investors trade for hedging (allocation) purposes, price changes tend to be temporary. For example, when investors buy stocks for hedging, the increase in buy orders pushes up the stock price in order to attract other investors to provide liquidity. However, the higher price is only temporary because the fundamental value of the stock remains unchanged. The price reverses the next day; hence, the returns are negatively autocorrelated.

LMSW test their prediction using its cross-sectional implication: the correlation between volume and return autocorrelation is more positive for stocks with a higher information asymmetry. Cross-sectional evidence, however, is susceptible to alternative interpretations

\footnotetext{
${ }^{1}$ The literature studies either returns, their volatility, or their autocorrelation. Morse (1980) was one of the first to examine the relation between total trading volume and return autocorrelation, and later Avramov, Chordia, and Goyal (2006), Campbell, Grossman, and Wang (1993), Conrad, Hameed, and Niden (1994), and Stickel and Verrecchia (1994) also studied the issue for either whole markets or individual stocks.
} 
because firm characteristics tend to be correlated. In contrast, this paper tests the time-series implications of the LMSW model by using subgroups of trading volume based on investor identity and trading direction.

There is both theoretical reasons and empirical evidence to assert that the volume subgroups we have chosen primarily reflect information trading. Institutional investors, a priori, are better informed than individual investors. On average, they are more sophisticated, better educated, and possess more resources to obtain and analyze private information. Consistent with the role of informed traders, Barber, Lee, Liu, and Odean, (forthcoming) found that both foreign investors and domestic mutual funds in Taiwan make profits from trading. Therefore, we have chosen foreign investors and domestic mutual funds as informed traders and use their trading volume to test the LMSW model. According to the LMSW model, we should find that returns are more positively autocorrelated when the trading volumes of foreigners or mutual funds are high. Our evidence is consistent with the prediction of the LMSW model, particularly in the case of large firms.

In addition to investor identity, we also classify trading volume based on trade direction, and posit that buy volume should contain more information than sell volume. When short selling is costly, investors with a piece of negative information are less likely to sell unless they already own the stock (Hong and Stein, 2002). In the most extreme case, short selling is prohibited outright, and the sell volume is less likely to convey information. Therefore, we expect to observe a less positive autocorrelation of returns when the sell volume is high than when the buy volume is high.

To test for the implication of the short-sale restriction, we utilized the sell volumes of both foreigners and mutual funds in Taiwan. Both groups of investors are prohibited by regulations 
from selling short. ${ }^{2}$ According to the LMSW model, we expected to observe a stronger positive autocorrelation when the buy volume of foreigners (or mutual funds) is high than when their sell volume is high. The evidence presented in this paper is consistent with this prediction.

The empirical findings on the difference between buy and sell volume contribute to the literature of short-sale constraints. Researchers have studied the various aspects of short-sale constraints such as the behavior of short sellers, the market response following short sale transactions, and the cross-sectional relation between overvaluation and short sale constraints. ${ }^{3}$ This paper examines a different issue. It identifies groups of investors who cannot sell short, and examines whether the market takes this into account and reacts differently to their buys and sales.

Our findings also have bearing on the literature concerning the role of order imbalance in asset markets (Brown, Walsh, and Yuen, 1997; Chan and Fong, 2000; Chordia, Roll, and Subrahmanyam, 2002; Chordia and Subrahmanyam, 2004). We argue that when short sale is constrained, buy and sell volume can have different price impacts, and we find such evidence. Therefore, to examine buy and sell volume separately may provide more information than to limit our investigation to order imbalance.

Our findings on the relationship between volume and return autocorrelation are related to Sias and Starks (1997). They find a positive cross-sectional relation between the autocorrelation of returns and institutional ownership. While the authors suggest that institutional trading is the underlying reason, they cannot test directly for this possibility due to

\footnotetext{
${ }^{2}$ Article 10 of the Regulations Governing Securities Investment Trust Funds forbids mutual funds and Article 21 of the Regulations Governing Investment in Securities by Overseas Chinese and Foreign Nationals forbids foreigners from selling short.

${ }^{3}$ Altken, Frino, McCorry and Swan (1998), Chang, Cheng and Yu (2007), Chen, Hong and Stein (2002), Dechow, Hutton, Meulbroek and Sloan (2001), Figlewski (1981), Jones and Lamont (2002).
} 
the limited availability of data. In this paper, we go one step further to show that trading is directly responsible for such a positive relation.

Another difference between this paper and the literature is that we are able to reveal the heterogeneity of institutional investors while Sias and Starks (1997) look only at the aggregate institutional ownership. ${ }^{4}$ Ex ante information discussed in Section 2 suggests that, unlike foreigners and mutual funds, dealers may trade for reasons other than private information. Given a liquidity-based trading, LMSW will predict a negative autocorrelation when dealers trade. Our evidence is consistent with such a prediction. Andrade, Chang, and Seasholes (2008) find that the imbalance of margin trading in Taiwan also creates price reversals. In their paper however, individuals are responsible for the margin trading and price reversals while dealers are responsible for our results.

The remainder of the paper is organized into five sections. Section 2 describes the trading mechanism in Taiwan and provides ex-ante information to identify the primary motivation of trading for different groups of institutional traders. Section 3 introduces the empirical method and data. Section 4 reports the main empirical results and supplementary results are provided in Section 5. Section 6 concludes.

2. The trading mechanism and institutional investors in Taiwan There are two stock markets in Taiwan: the Taiwan Stock Exchange (TSE) and the Gre Tai Securities Market (over-the-counter). Since 2001, trading has taken place between 9:00 a.m. and 1:30 p.m. Monday to Friday. Both markets are fully computerized and order driven. All orders are limit orders and the order book is not available to investors. Orders start to

\footnotetext{
${ }^{4}$ Yan and Zhang (forthcoming) use turnover to separate institutions into short-term and long-term investors and then separately examine the cross-sectional relation between their ownership and future stock returns.
} 
accumulate from 8:30 a.m. and unexecuted orders will only remain on the book until the end of the day, unless cancelled.

The stock markets in Taiwan have no market makers. Despite having no market makers and only four and a half hours of daily trading, trading in the stock markets is heavy. In 2006, the total trading value of the TSE was US\$736 billion with a turnover rate of $141 \%$. The over-the-counter market is smaller (a total trading value of US\$158 billion) but its turnover rate is even higher than the TSE at 333\%.

Domestic individual investors are crucial to the liquidity of Taiwan's markets. The trading share of domestic individuals was 83.7\% in 2001, and gradually declined to $73.1 \%$ in 2006 . Trading by foreign institutions makes up the difference: the trading share of foreign institutions increased from $5.6 \%$ to $14.1 \%$ in that period. By contrast, the trading share of domestic institutions did not change much during this period, growing only slightly to $11.1 \%$ in 2006 from $10.4 \%$ in 2001.

In this paper we examine the effect on return autocorrelation from three groups of institutional investors: foreigners, mutual funds, and dealers. We use two criteria - the type of orders submitted and their profitability - to judge the nature of the trade from a particular group of investor. If trading is information driven, investors should submit aggressive orders and make money out of them. If investors demands liquidity, they will submit aggressive orders but not necessarily make profits. If investors supply liquidity, they will submit passive orders and be profitable.

Our source of information on the type of orders submitted and their profitability is Barber, Lee, Liu, and Odean (forthcoming). The sample period used by Barber et al. is from 1995 to 1999, which is before our sample period (December 2000 to March 2007). Therefore, their results provide an ex-ante identification of the type of investor that we can rely on. 
For the type of orders submitted, Barber et al. reported in their 2005 version that all three groups of institutional investors submit predominantly aggressive orders. $91.8 \%$ of trades by dealers can be identified as aggressive or passive, and $62.4 \%$ is aggressive and $29.4 \%$ is passive. For foreigners, $93.5 \%$ of trades can be identified and $68.4 \%$ is aggressive. For mutual funds, $91.8 \%$ of trades can be identified and $60.4 \%$ is aggressive. Therefore, these institutional investors trade either to profit from information or to demand liquidity

For profitability, Barber et al. provided two measures of profitability (dollar profit in Table 4 and monthly return alpha in Table 6) over four holding periods (1 day, 10, 25, and 140 days). For aggressive orders, Barber et al. found that both foreigners and mutual funds have significantly positive profitability for both measures over all four holding periods. Therefore, both foreigners and mutual funds appear to trade on information because they submit aggressive orders and make profits. According to the LMSW model, we should find that returns are more positively autocorrelated when the trading volumes of foreigners or mutual funds are high.

On the other hand, dealers do not make profits consistently. Out of eight profitability numbers, only three are significantly positive and three numbers are even negative. Therefore, compared with foreigners and mutual funds, dealers are less likely to trade on information and LMSW will predict that returns are less positively autocorrelated when dealers trade heavily.

Dealers are less likely to trade on information because trading profit is not their only objective. In Taiwan, the term "dealer" represents securities companies that trade for their own accounts. Conversations with local practitioners suggest that trading in securities companies sometimes serves a purpose other than direct profits. Large securities companies have several business divisions that include investment banking as well as trading. If the business in the investment bank division has risk exposure, the trading division will hedge accordingly. A lack 
of profitability observed in Barber et al. is consistent with the hedging demand as a motivation of trading.

3. Empirical method and data

We begin by introducing the empirical method. Subsequently, we discuss our sample and the data used.

\subsection{Empirical method}

The regression model starts from the following specification:

$$
R_{t+1}=C_{0}+C_{1} R_{t}+\beta V_{t} R_{t}+\varepsilon_{t+1},
$$

where $R_{t}$ is the daily return and $V_{t}$ is the daily total volume at time $t$. We follow LMSW to define $V_{t}$ as the detrended natural logarithmic of the daily turnover (number of total shares traded divided by the number of outstanding shares). Before taking the log we first add a small number $(0.00000255)$ to the turnover to avoid zero trading volume. We then detrend the series by subtracting a 200-day moving average:

$$
\begin{aligned}
& V_{t}=\text { lturnover }_{t}-\frac{1}{200} \sum_{s=1}^{200} \text { lturnover }_{t-s} \\
& \text { lturnover }_{t}=\ln \left(\text { turnover }_{t}+0.00000255\right)
\end{aligned}
$$

Equation (1) allows the first-order autocorrelation coefficient of returns to be a function of trading volume. If, on average, investors trade on information, then the coefficient on volume ( $\beta$ ) will be positive, whereas if investors trade to hedge, then $\beta$ will be negative. LMSW test their model by examining the cross-sectional relation between $\beta$ and firm variables 
that measure the degree of information asymmetry.

We propose to test the LMSW model by allowing $\beta$ to be time-varying and using institutional trading volumes to identify periods of intensive information trading. The first specification uses only dummy variables as follows:

$$
\begin{aligned}
\beta_{t}= & C_{2}+C_{F B} D_{t}^{F B} D_{t[R>0]}+C_{F S} D_{t}^{F S} D_{t[R \leq 0]}+C_{M B} D_{t}^{M B} D_{t[R>0]}+C_{M S} D_{t}^{M S} D_{t[R \leq 0]}+ \\
& C_{D B} D_{t}^{D B} D_{t[R>0]}+C_{D S} D_{t}^{D S} D_{t[R \leq 0]}
\end{aligned}
$$

$D_{t[R>0]}\left(D_{t[R \leqq 0]}\right)$ is a dummy variable that equals one if $\mathrm{R}_{\mathrm{t}}>0\left(\mathrm{R}_{\mathrm{t}} \leqq 0\right)$. $D_{t}^{F B}$ is a dummy variable that equals one if the daily buy turnover (buy volume, which we denote by the superscript $B$, divided by the number of shares outstanding) from foreigners (superscript $F$ ) is higher than its 200-day moving average. $D_{t}^{F S}, D_{t}^{M B}, D_{t}^{M S}, D_{t}^{D B}$, and $D_{t}^{D S}$ are defined similarly, where superscript $S$ denotes sell volume, $M$ denotes mutual funds, and $D$ denotes dealers. In contrast to total volume, we do not use log turnover to define dummy variables. Taking logs here will reduce the importance of large institutional volumes, which we use to test the LMSW's predictions, and reduce the power of our tests.

Our specification assumes a different autocorrelation coefficient of returns only if the direction of heavy institutional trades is the same as the direction of returns, that is, when the daily return is positive and institutional buy is heavy or when the daily return is negative and institutional sell is heavy. This specification follows the LMSW model that trading based on good information drives up the price while trading based on bad information causes the price to drop. For brevity, in the rest of the paper when I say heavy buy, I mean heavy buy on a positive-return day. Similarly, when I say heavy sell, I mean heavy sell on a negative-return day. 
Given that, on average, foreigners and mutual funds trade on information, trading is more likely driven by information when foreigners or mutual funds trade more extensively. Therefore, when the trading volume of foreigners or mutual funds is high relative to its moving average, the autocorrelation coefficient is higher. The coefficients $C_{F B}, C_{F S}, C_{M B}$, and $C_{M S}$ in equation (3) should be positive, in accordance with the LMSW model.

The second hypothesis that we test stipulates that the buy volumes of foreigners and mutual funds generate a more positive autocorrelation than sell volume because the short-sale constraint will make sell volume contain less information (Hong and Stein, 2002). If the buy volume is more information driven than the sell volume, then $C_{F B}$ should be greater than $C_{F S}$ and $C_{M B}$ should be greater than $C_{M S}$.

On the other hand, dealers are less likely to trade on information. Thus, the autocorrelation coefficient on days of heavy trading from dealers is lower than the coefficient on days of heavy trading from foreigners or mutual funds. The coefficients $C_{D B}$ and $C_{D S}$ in equation (3) should be less than coefficients $C_{F B}, C_{F S}, C_{M B}$, and $C_{M S}$, in accordance with the LMSW model.

The second specification that we use directly employs institutional trading volume by decomposing total volume into its components as in the following:

$$
\begin{aligned}
\beta_{t} V_{t}= & C_{2} V_{t}^{O}+C_{F B} Q_{t}^{F B} D_{t[R>0]}+C_{F S} Q_{t}^{F S} D_{t[R \leqq 0]}+C_{M B} Q_{t}^{M B} D_{t[R>0]}+C_{M S} Q_{t}^{M S} D_{t[R \leqq 0]}+ \\
& C_{D B} Q_{t}^{D B} D_{t[R>0]}+C_{D S} Q_{t}^{D S} D_{t[R \leqq 0]}
\end{aligned}
$$

where $V_{t}^{O}$ is the natural logarithmic of the daily turnover from investors other than foreigners, mutual funds, and dealers. $Q_{t}^{F B}$ is the daily buy turnover from foreigners divided by turnover from others. $Q_{t}^{F S}, Q_{t}^{M B}, Q_{t}^{M S}, Q_{t}^{D B}$, and $Q_{t}^{D S}$ are defined similarly. Notice that we define $V_{t}^{O}$ 
and $Q$ differently: the former as the log of volumes and the latter as the ratio of volumes. The reason is because the log of the sum of volumes is not equal to the sum of log volumes.

To obtain the decomposition in (4), we use the following approximation:

$$
\begin{aligned}
\text { turnover }_{t} & =\text { turnover }_{t}^{0}\left(1+Q_{t}^{F B}+Q_{t}^{F S}+Q_{t}^{M B}+Q_{t}^{M S}+Q_{t}^{D B}+Q_{t}^{D S}\right) \\
& \approx \text { turnover }_{t}^{0}\left(1+Q_{t}^{F B}\right)\left(1+Q_{t}^{F S}\right)\left(1+Q_{t}^{M B}\right)\left(1+Q_{t}^{M S}\right)\left(1+Q_{t}^{D B}\right)\left(1+Q_{t}^{D S}\right)
\end{aligned}
$$

Taking logs of both sides of the approximation (5) gives us the decomposition: $\mathrm{V}_{\mathrm{t}}=\ln \left(\right.$ turnover $\left._{t}\right) \approx V_{t}^{0}+Q_{t}^{F B}+Q_{t}^{F S}+Q_{t}^{M B}+Q_{t}^{M S}+Q_{t}^{D B}+Q_{t}^{D S}$

Substituting equations (3) or (4) into (1) gives the regression models (6) and (7):

$$
\begin{aligned}
R_{t+1}= & C_{0}+C_{1} R_{t}+C_{2} V_{t} R_{t}+C_{F B} D_{t}^{F B} D_{t[R>0]} V_{t} R_{t}+C_{F S} D_{t}^{F S} D_{t[R \leqq 0]} V_{t} R_{t}+ \\
& C_{M B} D_{t}^{M B} D_{t[R>0]} V_{t} R_{t}+C_{M S} D_{t}^{M S} D_{t[R \leqq 0]} V_{t} R_{t}+C_{D B} D_{t}^{D B} D_{t[R>0]} V_{t} R_{t}+ \\
& C_{D S} D_{t}^{D S} D_{t[R \leqq 0]} V_{t} R_{t}+\varepsilon_{t+1 .}, \\
R_{t+1}= & C_{0}+C_{1} R_{t}+C_{2} V_{t}^{O} R_{t}+C_{F B} Q_{t}^{F B} D_{t[R>0]} R_{t}+C_{F S} Q_{t}^{F S} D_{t[R \leqq 0]} R_{t}+ \\
& C_{M B} Q_{t}^{M B} D_{t[R>0]} R_{t}+C_{M S} Q_{t}^{M S} D_{t[R \leqq 0]} R_{t}+C_{D B} Q_{t}^{D B} D_{t[R>0]} R_{t}+C_{D S} Q_{t}^{D} D_{t[R \leqq 0]} R_{t}+\varepsilon_{t+1 .},
\end{aligned}
$$

We use a two step procedure to estimate coefficients in models (6) and (7). The first step is to run time-series regression for each stock to get the OLS estimate of coefficients. When any one group of institutional investors does not trade a given stock at all, its dummy variable is removed from the regression. We then estimate a cross-sectional average of the coefficients 
by running a robust regression that has only the intercept term. We use the STATA software rreg command to estimate the intercept. A robust regression estimate is designed to deal with extreme observations with statistical validity. It is a form of weighted least-squares that first drops the most influential observations and then imposes smaller weights on observations with larger absolute residuals (Baker and Hall, 2004; Li, 1985). We have also estimated the mean with winsorizing or trimming at the $5^{\text {th }}$ and $95^{\text {th }}$ percentiles, the results are very similar.

\subsection{Data}

The availability of data on the trading volumes of institutional investors determines our sample period. The sample period begins on December 12, 2000, the day when local markets began to disclose the daily number of shares bought and sold by three groups of institutional investors - foreigners, mutual funds, and dealers. The sample period ends on March 30, 2007, and includes 1,558 trading days in total. To be included in the sample, stocks are required a minimum number of 750 daily observations. ${ }^{5}$ The final sample includes 1,049 common stocks traded on the TSE or the over-the-counter market. The data source is the Taiwan Economic Journal Database.

Table 1 reports the summary statistics for the variables used. We first calculate the time-series statistics of the variable of interest for each stock, and then report its $25^{\text {th }}, 50^{\text {th }}$ (median), and $75^{\text {th }}$ percentiles across stocks. Because buy and sell from institutions have similar statistics, we choose to report the statistics for buy volume only.

Daily returns are positively autocorrelated. The first-order autocorrelations of daily returns are predominantly positive: the $25^{\text {th }}$ percentile is 0.03 and the median is 0.08 . The positive autocorrelations suggest that the market takes time to reflect information.

\footnotetext{
5 There are 185 stocks are deleted due to this requirement. We have also tried to require a minimum number of 450 daily observations and obtained similar results.
} 
Trading in Taiwan is strongly autocorrelated. Although not reported, the first-order autocorrelation of the daily turnover is high, with a $25^{\text {th }}$ percentile of 0.64 . The detrending procedure (deduct the 200-day moving average) does not reduce the autocorrelation. Table 1 reports that the $25^{\text {th }}$ percentile of the first-order autocorrelation of the detrended log turnover is still 0.64.

Trading from institutional investors is less autocorrelated than other investors. The medians of autocorrelation coefficients from the three groups of institutional investors range from 0.24 to 0.36 . Part of the positive autocorrelation of institutional trading is caused by order splitting (Lee, Liu, Roll, and Subrahmany, 2004).

Institutions do not trade very often. The median of the percentage of non-zero days is only $6 \%$ for mutual funds. It means that, for more than half of the sample stocks, mutual funds do not make any purchases on $94 \%$ of the trading days. Compared with other institutions, dealers trade more frequently. But even dealers do not make any purchase on $81 \%$ of the trading days for more than half of the sample stocks.

Institutional trades are concentrated on the days they trade. Take the buy turnover of mutual funds as an example; its standard deviation is $0.052 \%$, which is more than six times larger than the mean (0.0077\%) and suggests the existence of large trades. Given that heavy trades are unusual; these trades have the potential to move the price as the LSMW model suggests. To identify heavy trades from mutual funds, we use its 200-day moving average as the benchmark. On average, $22.6 \%$ of trading days are identified as heavy buy from mutual funds. Similarly, $25.2 \%$ and $25.9 \%$ of trading days are identified as heavy buys from foreigners and dealers. 


\section{Empirical results}

We begin by presenting empirical results for two basic regression models. Then we examine whether the autocorrelation reflects market information, industry information, or idiosyncratic information. We also examine whether the autocorrelation reflects public or private information.

\subsection{Basic results}

To test the time-series implications of the LMSW model, we first estimate regression model (6). In model (6), the autocorrelation on days of heavy institutional buy or sell is estimated separately using dummy variables. Table 2 reports the estimation results. Panel A lists the average over all firms.

The $1^{\text {st }}$ column of Panel A reports the average estimated from a robust regression. We first look at the coefficient $\mathrm{C}_{2}$, which is the autocorrelation on the days when the trading of institutional investors is low. The coefficient estimate is 0.003 and is not significantly different from zero. By contrast, on the days when foreigners or mutual funds trade heavily, the average autocorrelation coefficients are significantly higher. For example, the average autocorrelation coefficient on days with a heavy buy from mutual funds $\left(\mathrm{C}_{\mathrm{MB}}\right)$ is 0.049 and is significantly positive. This is consistent with the LMSW prediction that information trading will generate positive autocorrelations.

The next question is whether buy volume has a different autocorrelation pattern from sell volume. The test results are reported in the last three rows of Panel A. For foreigners, the coefficient on days with heavy sell ( $\mathrm{C}_{\mathrm{FS}}$ estimate is 0.025$)$ is no different from the days with heavy buy ( $\mathrm{C}_{\mathrm{FB}}$ estimate is 0.020$)$. On the other hand, the coefficient on days with heavy sell from mutual fund $\left(\mathrm{C}_{\mathrm{MS}}\right)$ is -0.005 . It is significantly smaller than the coefficient on days with heavy buy ( $\mathrm{C}_{\mathrm{MB}}$ estimate is 0.049$)$. The evidence on mutual funds supports our hypothesis that, 
due to short-sale constraints, sell volume contains less information than buy volume.

Dealers behave very differently from foreigners and mutual funds. The average autocorrelation coefficients on days with heavy trades from dealers are significantly negative. This evidence is consistent with our ex-ante identification that trading from dealers is less information driven than from foreigners and mutual funds.

In addition to estimate the average using a robust regression, we also tried other methods to reduce the influence of extreme observations. The $2^{\text {nd }}$ column of Panel A of Table 2 reports the average estimates after trimming the sample at the $5^{\text {th }}$ and $95^{\text {th }}$ percentiles; column 3 gives the average estimated by winsorizing at the same percentiles. The estimates from three methods are very similar. Therefore, in the following we will only report the average estimated from robust regressions.

Panel B of Table 2 reports the average coefficients of four size quartiles. The average coefficients on $V_{t} * R_{t}$ are negative for large firms and positive for small firms. This cross-sectional pattern is similar to LMSW's findings and consistent with their hypothesis that trading is more information driven for small firms, which have more information asymmetry.

The cross-sectional pattern of autocorrelation coefficients on days with heavy institutional trading is very different. When foreigners or mutual funds trade heavily, the average coefficients for large firms are significantly positive, but the coefficients for small firms are not. Therefore, institutions trade on information of large firms, not small firms. This evidence is consistent with the argument that the incentive to gather private information is stronger for large firms because institutional investors can trade large positions to make a profit. This is also consistent with findings in the literature that foreigners and mutual funds prefer to invest in large firms (Falkenstein, 1996; Kang and Stulz, 1997). 


\section{$<$ INSERT TABLE 2>}

We also test the LMSW model using the regression model (7) which directly employs institutional volume in the regression rather than dummy variables. Table 3 reports the estimation results. Qualitatively, the results are very similar to Table 2 except that the difference between buy and sell volume is stronger in Table 3. For foreigners, high sell volume does not come with a higher average autocorrelation coefficient for the whole sample. Rather, it comes with a significantly lower average autocorrelation coefficient for one of the small firm quartiles. For both foreigners and mutual funds, there is strong evidence that buy volume contains more information than sell volume. By contrast, there is no significant difference between buy and sell from dealers, who do not face the short-sale constraint. Hence, our evidence supports the hypothesis that the short-sale constraint will reduce the information content of sell volume.

\section{$<$ INSERT TABLE 3>}

\subsection{Robustness check}

When we test the significance of the average coefficient in Tables 2 and 3, we assume zero correlations between coefficients. This assumption is not correct If the error terms from the $1^{\text {st }}$ step time-series regressions are correlated across stocks. To reduce the cross-sectional correlation between error terms, we follow Jorion (1990) to add the market return (MR) and the industry return $(I R)$ to the time-series regressions as follows: 


$$
\begin{aligned}
R_{t+1}= & C_{0}+C_{1} R_{t}+C_{2} V_{t} R_{t}+C_{F B} D_{t}^{F B} D_{t[R>0]} V_{t} R_{t}+C_{F S} D_{t}^{F S} D_{t[R \leqq 0]} V_{t} R_{t}+C_{M B} D_{t}^{M B} D_{t[R>0]} V_{t} R_{t}+ \\
& C_{M S} D_{t}^{M S} D_{t[R \leqq 0]} V_{t} R_{t}+C_{D B} D_{t}^{D B} D_{t[R>0]} V_{t} R_{t}+ \\
& C_{D S} D_{t}^{D S} D_{t[R \leqq 0]} V_{t} R_{t}+C_{3} M R_{t+1}+C_{4} I R_{t+1}+\varepsilon_{t+1}
\end{aligned}
$$

Column (1) of Table 4 reports the coefficient estimates of model (8). The coefficients on market return and industry return are both significantly positive, but their significance does not change the significance of institutional trading. Results in Table 4 are very similar to Table 2. Therefore, our inferences are not driven by the cross-sectional correlation.

Results in Table 4 also suggest that trading by foreigners and mutual funds are based on firm-specific information rather than market or industry wide information. Including the market and industry returns in the regression scarcely changes the coefficients on institutional trading. For example, the coefficient on foreigner (mutual fund) buying is 0.0195 (0.0487) in Table 2, and $0.0136(0.0406)$ when market and industry returns are included with regressions in Table 4.

Including the market and industry returns in the regression does not guarantee the isolation of the firm-specific volume. As an alternative, we follow LMSW to estimate firm-specific returns and volumes and use them in the regression model (6). The firm-specific returns and volumes are residuals of market models for returns and the detrended log turnover. The market return is defined as the change in the log of the Taiwan Stock Exchange Value-weighted Index. The market turnover used in the market model is the detrended natural logarithmic (as in equation (2)) of the market turnover, which equals the total value of shares traded on the Taiwan Stock Exchange divided by the total market capitalization. We report results using firm-specific returns and volumes in columns (2) and (3) of Table 4.

The difference between columns (2) and (3) is in the definition of the dummy variables 
that measure the extent of institutional trading. The definition used in column (2) is the same as the one used in Table 2. Take the dummy variable for foreigners' buy as an example: foreigners' buy is heavy if the buy turnover is greater than its 200-day moving average. The definition used in column (3) is the firm-specific component of foreigners' buy. We first estimate a market model by regressing foreigners' buy turnover against the market turnover. Foreigners' buy is heavy if the residual of the market model is greater than its 200-day moving average. As mentioned earlier, we do not use the log of institutional turnover to define dummy variables because that will reduce the power of our tests.

The qualitative results in columns (2) and (3) of Table 4 are similar to results in Table 2. Take the coefficient on mutual fund buying as an example: it is 0.0487 in Table 2, 0.0402 in column (2), and 0.0295 in column (3). Therefore, the effect of institutional trades on autocorrelation is mainly driven by firm-specific information.

\section{$<$ INSERT TABLE 4>}

The next question we address is whether the autocorrelated return on the next day reflects public or private information. Suppose the information is positive. The positive return on the next day can reflect private information revealed by more purchase on the next day from institutions. The same institution can split its orders into several days to reduce the price impact (Kyle, 1985). Several institutions may receive noisy private signals of the same underlying information sequentially and trade on them (Hirshleifer, Subrahmanyam, and Titman, 1994). In either scenario, positive autocorrelations occur when institutions make heavy purchase consecutively.

On the other hand, if institutions receive private information and trade on it just prior to 
its public announcement, then the return on the next day will reflect the public announcement. In the LMSW model, the public announcement on the next day will cause the informed trader to trade on the opposite side. ${ }^{6}$ Suppose the good information becomes public on date $t+1$, the uninformed traders will revise upward their expectation of the fundamental value and increase their demand. The price will go up. Given that the price is higher, the informed traders who have the same expectation of the fundamental value on date $t$ and $t+1$ will reduce their demand on date $t+1$. Therefore, informed traders will buy the stock on date $t$ and sell it on date $t+1$.

To distinguish between the public and private information stories, we expand the regression model (6) to the following one (9),

$$
\begin{aligned}
R_{t+1}= & C_{0}+C_{l} R_{t}+C_{2} V_{t} R_{t}+\left(C_{F B}+C_{F B B} D_{t+1}^{F B}+C_{F B S} D_{t+1}^{F S}\right) D_{t}^{F B} D_{t[R>0]} V_{t} R_{t}+\left(C_{F S}+\right. \\
& \left.C_{F S S} D_{t+1}^{F S}+C_{F S B} D_{t+1}^{F B}\right) D_{t}^{F S} D_{t[R \leq 0]} V_{t} R_{t} \\
& +\left(C_{M B}+C_{M B B} D_{t+1}^{M B}+C_{M B S} D_{t+1}^{M S}\right) D_{t}^{M B} D_{t[R>0]} V_{t} R_{t} \\
& +\left(C_{M S}+C_{M S S} D_{t+1}^{M S}+C_{M S B} D_{t+1}^{M B}\right) D_{t}^{M S} D_{t[R \leq 0]} V_{t} R_{t} \\
& +C_{D B} D_{t}^{D B} D_{t[R>0]} V_{t} R_{t}+C_{D S} D_{t}^{D S} D_{t[R \leq 0]} V_{t} R_{t}+\varepsilon_{t+1}
\end{aligned}
$$

We decompose the coefficients on dummy variables into three parts depending on the trading direction on the next day. Take the heavy buy from mutual funds as an example. In regression model (6), the coefficient on the dummy variable $D_{t}^{M B}$ that captures heavy buys from mutual funds is $C_{M B}$. Now we have three coefficients: $C_{M B}, C_{M B B}$, and $C_{M B S}$. The first part $C_{M B}$ is the same as before. The second part $C_{M B B}$ captures the days when a heavy buy is followed by another heavy buy from mutual funds. Under the private information story $C_{M B B}$ is positive. The third part $C_{M B S}$ captures the days when a heavy buy is followed by a heavy sale

\footnotetext{
${ }^{6}$ We would like to thank an anonymous referee for pointing this out.
} 
from mutual funds. $C_{M B S}$ is positive under the public information story. We apply the same decomposition to buy and sell from foreigners and mutual funds. For the trading from dealers, we do not decompose the coefficients because it is not information driven.

Table 5 reports the coefficient estimates. The first thing to notice is that the autocorrelation coefficients are almost always negative $\left(C_{F B}, C_{M B}\right.$, and $\left.C_{M S}\right)$ when a heavy trade is not followed by another heavy trade. It suggests that heavy trade for only one day is more likely to be allocation trade than information trade.

When a heavy trade is followed by another heavy trade on the same directions, the autocorrelation coefficients are significantly higher, that is, $C_{F B B}, C_{F S S}, C_{M B B}$, and $C_{M S S}$ are significantly positive. By contrast, when trading on the next day is on the opposite direction most of the coefficients $\left(C_{F S B}, C_{M B S}, C_{M S B}\right)$ are significantly negative. The evidence is consistent with the private information story and the significance of the positive autocorrelation primarily reflects private information revealed by trading on $t+1$. However, without detailed data, we cannot determine whether this trading is caused by order splitting from the same institutions or by trading from different institutions.

\section{$<$ INSERT TABLE 5>}

Another issue of concern is whether applying the same one-day estimation interval for all stocks is reasonable. In LMSW's model, the positive autocorrelation reflects partial information revealed in trading and its further revelation in the future. Therefore, the appropriate interval is the one which includes enough trades to partially reflect the information, but not too long to fully reflect the information within the interval. For an illiquid stock, a one-day interval may not include enough trades to reflect information. On the other hand, for a 
liquid stock, a multiple-day interval can reduce the magnitude and the significance of the autocorrelation coefficient if the interval used is longer than the number of days required to fully reflecting information.

To allow the estimation interval differ across stocks we follow the idea used by LMSW: more days will be included in the estimation interval for low turnover stocks. We first calculate the median daily turnover for each stock, and sort all stocks into three groups based on the median turnover. The cross-sectional median of the median turnover for the three groups are 0.1058\%, 0.3507\%, and $0.9011 \%$, respectively. As a result, we estimate the regression model (6) by using a one-day interval for high turnover stocks, a three-day interval for middle turnover, and an eight-day interval for low turnover stocks. For a multiple-day interval, the return is compounded daily return and the turnover is the sum of daily turnover.

Table 6 reports the estimation results. When the measurement interval is lengthened, there is less evidence of a higher autocorrelation during heavy institutional trading. Compared with Table 2, what remains unchanged is the positive autocorrelation coefficient during heavy buying from mutual funds. The point estimate 0.0246 is smaller than the number in Table 2 (0.0487), but is significant at a 1\% level. For foreign investors the effect of heavy buying on autocorrelation is not significant for the whole sample, but it is still significant for large firms. The smaller autocorrelation coefficients suggest that, for some stocks, the multiple-day interval is longer than the number of days required to fully reflecting information.

On the other hand, the autocorrelation coefficients on days when foreigners or mutual funds sell heavily are not significantly different from other days when we move to a multiple-day interval. This suggests that the effect of information-based selling is quick to be fully reflected in the price.

There is evidence that, for two small size quartiles, the average autocorrelations are 
significantly negative when foreigners buy heavily. It is not consistent with our ex-ante identification that foreigners are informed traders. However, these stocks are very small. The total market capitalization of the two small size quartiles is less than $5 \%$ of the aggregate market capitalization. Given the small size, the purchase from foreigners may cause a temporary impact and price reversal.

\section{$<$ INSERT TABLE 6>}

To summarize, we find evidence that is consistent with the LMSW model's prediction that information trading generates positive autocorrelations. We also find that, due to short-sale constraints imposed on foreigners and mutual funds, their selling has less information content and causes smaller autocorrelations.

\section{Additional evidence}

In this Section, we first examine how information-based trading will be affected when there are derivative products. Then we simulate a portfolio strategy that exploits the regression results that the autocorrelation coefficient depends on the trading of institutional investors. Portfolio returns can provide us a natural metric to examine the economic significance of the predictability of institutional trading.

\subsection{Existence of derivative products}

In this section, we examine the effects of derivative markets on return dynamics. On the TSE, securities companies can issue call or put covered warrants for investors to trade. A covered warrant contract is very similar to an option contract, with the exception that covered warrants are issued by securities companies and listed on stock exchanges. 
When covered warrant contracts are traded, investors have a stronger incentive to trade for information. The covered warrant contracts are highly levered and less costly to trade. Therefore, the incentive to collect information increases and institutional investors collect more information to trade on. Investors can then trade on either the equity market or the warrant market to make a profit, depending on the prevailing price and trading cost. If institutional investors sometimes trade on the equity market, then the autocorrelation coefficient on days with large buys will be higher.

To test our prediction, we examine the difference between stocks that have warrants and those that do not and report results in Table 7. As only large firms have covered warrants, we examine the third and fourth (the two largest) size quartile firms to control for the size effect.

\section{$<$ INSERT TABLE 7>}

The average autocorrelation coefficients on days with large buys from foreigners or mutual funds are significantly positive for stocks with or without warrants. However, the coefficients are at least $60 \%$ larger when there are warrants and the differences are statistically significant. Therefore, the evidence is consistent with our prediction that derivative products increase information trading and affect the autocorrelation structure of returns.

The existence of warrants, on the other hand, does not significantly change average autocorrelation coefficients on days with large institutional sells. This evidence is consistent with the fact that stocks cannot be sold short with or without the existence of warrants.

\subsection{Portfolio returns}

Given the statistical evidence that autocorrelation coefficients are different during heavy 
institutional trading, we want to examine the profitability of a trading strategy that exploits the time-varying autocorrelation coefficients. The profitability provides a measure of economic significance.

We begin with a benchmark strategy that buys stocks with a positive return and sell them with a negative return. This strategy should generate a positive return given that the average autocorrelation coefficient is positive. During the sample period, we divide all stocks into two groups based on the sign of the return on day t: one group contains all stocks with positive returns and the second group contains stocks with negative returns. For each group, we first calculate the equal-weighted average return on day $t+1$ and then calculate its time-series average return over the sample period. To test the significance of the average return, we use the Newey-West standard errors of ten lags to account for possible autocorrelations of daily returns. The positive-return group generates an average daily return of $0.21 \%$ and the negative-return group generates an average of $-0.05 \%$. The return of an arbitrage portfolio that longs the positive return and shorts the negative is $0.26 \%$ and is significant at a 0.01 level. Despite the statistical significance, its magnitude is small compared with a transaction cost of $0.895 \%$ (See Appendix for the estimation of the transaction cost).

To exploit the finding of autocorrelation on heavy trading days, we construct the following four portfolios. The first portfolio includes stocks that have heavy total trading volume (higher than its 200-day moving average), heavy institutional buy, and positive return on day t. The second portfolio includes stocks that have heavy total volume, heavy institutional selling, and negative return on day t. The third and fourth portfolios are similar to the first two portfolios except that they include stocks that have low, rather than high, institutional buy or sell. The criteria used to construct portfolios arise from the prediction of the LMSW model: the autocorrelation of returns is higher when total volume is high and the direction of the 
information trading is the same as the direction of returns.

Table 8 reports portfolio returns on day $\mathrm{t}+1$. Panel A, B, and C report separately the portfolios based on trading from mutual funds, foreigners, and dealers. One thing common is that returns on portfolios based on a positive return on day t are all positive (columns 1 and 3) and that returns on portfolios based on a negative return on day t are all negative (columns 2 and 4). This reflects the fact that returns are positively autocorrelated.

When mutual funds and foreigners buy more on a positive-return day, the return on the next day is higher. For example, for the portfolio with large mutual fund buys, the average return on the next day is $0.51 \%$ (column 1 , Panel A), whereas for the portfolio with light mutual fund buys and positive returns, the average return is $0.24 \%$ (column 3 ). The difference in return is $0.26 \%$ (column 5) and is significant at a 0.01 level. The significant difference is consistent with the LMSW's prediction that information trading increases the autocorrelation of returns.

Similarly, the portfolio return is more negative if mutual funds sell heavily on a negative-return day. The difference in return is $-0.03 \%$, which is not significantly different from zero at a 0.1 level. This nonsignificant difference is consistent with our hypothesis that sell volumes contain less information than bye volumes due to short sale constraints.

If we form an arbitrage portfolio that longs the portfolio with large mutual fund buy and shorts the portfolio with large mutual fund sell, the average return is $0.66 \%$ (column 7 ) and is more than twice the return on a arbitrage portfolio that only exploits autocorrelation but ignores institutional trading.

$<$ INSERT TABLE 8> 
The pattern is different for portfolios based on dealers' trading. When dealers buy more on a positive-return day, the return on the next day is lower rather than higher. For the portfolio with large buys from dealers, the average return is $0.24 \%$ (column 1 , Panel C), whereas for the portfolio with light dealer-buys, the average return is $0.33 \%$ (column 3). The difference in return $-0.09 \%$ (column 5) and is significant at a 0.01 level. The significant difference is consistent with the earlier finding that dealer's trading reduces the autocorrelation of returns.

Andrade, Chang, and Seasholes (2008) find that the change in shares held in margin accounts in Taiwan is a measure of liquidity demand and is related to price reversals. If we take their measure of liquidity demand into account, does it increase or reduce the return of our arbitrage portfolios? If foreigners or mutual funds happen to trade against margin traders, then our results may recede and the return of our arbitrage portfolios will drop significantly. On the other extreme, if the direction of margin trading is the same as the trading by foreigners or mutual funds, we can improve the return of our arbitrage portfolios by taking the margin trading into account.

Following Andrade, Chang, and Seasholes (2008), we calculate the daily change in shares for each stock held in margin accounts normalized by the number of shares outstanding. We first calculate the correlation coefficients between the imbalance of margin trading and institutional buy or sell volume for each stock and then take the cross-sectional average. The average correlation coefficients are not high; they range from -0.05 to 0.13 . Therefore, the imbalance of margin trading is only weakly related to institutional buys or sells.

Next, we examine the profitability of portfolios taking into account both the imbalance of margin trading and institutional trading. Each day, we sort all stocks with heavy trading volume into one of six portfolios based on institutional trading and margin trading. There are three groups (low, medium, and high) of margin trading using the $20^{\text {th }}$ and $80^{\text {th }}$ percentile of 
the imbalance of margin trading as the cutoff points. There are two groups of institutional trading: large institutional buys on a positive-return day and large institutional sells on a negative-return day. We calculate the time-series average return for each portfolio and report them in Table 9.

As found in Andrade, Chang, and Seasholes (2008), the higher the imbalance of margin trading, the lower the return on the following day. Holding the institutional trading constant, the differences in the average return between the low and high imbalance of margin trading are all positive and range from $0.29 \%$ to $0.52 \%$.

Taking into account the imbalance of margin trading, however, does not change our conclusion that the arbitrage portfolios based on institutional trading are profitable. Holding the imbalance of margin trading constant, the average return of arbitrage portfolios remains positive with a range from $0.44 \%$ to $0.88 \%$. Therefore, our results are not driven by the liquidity demand of margin traders.

\section{$<$ INSERT TABLE 9>}

We can even improve the performance of our arbitrage portfolios if we combine information trading with margin trading. For example, we can long the portfolio that includes stocks with a low imbalance of margin trading and a strong buy from mutual funds, and short the portfolio that includes a high imbalance of margin trading and a strong sell from mutual funds. The average daily return of the improved arbitrage portfolio would be $1.17 \%$, which is higher than the estimated round trip transaction cost of $0.895 \%$.

\section{Conclusion}


Llorente, Michaely, Saar, and Wang (2002) show that trading based on information can cause a positive autocorrelation of returns. We test this hypothesis using the identification condition that foreigners and mutual funds trade on information. Consistent with the hypothesis, we find that the autocorrelation of returns is higher when foreigners and mutual funds trade more heavily. We also hypothesize that short sale constraints will reduce the information content of sell volume and reduce the autocorrelation accordingly. The second hypothesis is also supported by our evidence that the sell volume from mutual funds and foreigners has a smaller effect on the autocorrelation of returns than buy volume.

Our results can help to better understand the time-series behaviors concerning the autocorrelations of returns. Bessembinder and Hertzel (1993) find a pattern in the autocorrelation of security returns around non-trading days. This pattern may be related to the information trading around those days. Future investigations may be warranted.

Our results also suggest that institutional investors in Taiwan are heterogeneous. In particular, dealers have a different impact on the autocorrelation of returns compared with foreigners and mutual funds. This suggests that dealers have a different incentive that is worth pursuing in the future. 
Appendix: Estimate the transaction cost in a call auction market

Trading on the stock exchanges in Taiwan involves two call auction mechanisms: a periodic call used to open trading and a batch call used throughout the day (the trading interval between each call is less than one minute). In both auction mechanisms, orders accumulate and the computer sets a single market-clearing price at which demand equals supply and all executed orders transact. The priority of the order execution depends first on the price and then on the arrival time of orders.

In an auction market, investors cannot trade immediately. Both a market order to buy and a market order to sell have to wait and transact at the same market-clearing price. Therefore, the widely used measures in continuous auction markets, such as the quoted spreads or the effective spread, cannot be used to measure the transaction cost in call auction markets.

To measure the transaction cost in call auction markets, we use the concept of trading friction discussed in Stoll (2000). The trading friction, in Stoll's words, "is the real resources used up or extracted as monopoly rents to accomplish trades”. Stoll suggests that one can measure dynamic trading friction with "the temporary price change associated with trading”.

In a call auction market, not every investor has to pay a transaction cost in Stoll's sense. For a given order submitted, the existence of a transaction cost in terms of a temporary price change depends on whether it belongs to the more aggressive side of orders submitted for the same call. For example, if large aggressive buy orders arrive for a liquidity reason, the transaction price will be pushed up temporarily. The price will drop later given the fundamental value does not change. Therefore, investors who submit buy orders will pay a higher price, which is part of the transaction cost incurred. Investors who submit sell orders around the same time for whatever reasons do not have to sell at a lower price given their sell 
orders are less aggressive than buy orders. Instead, they can sell at a higher price to investors who demands liquidity the most. Therefore, the transaction cost for investors on the less aggressive side of the trade will actually be lower.

To estimate the temporary price change associated with trading for individual stocks, we run the following regression with daily data:

$$
\mathrm{r}_{\mathrm{t}}=\mathrm{a}_{0}+\mathrm{b}_{1} \mathrm{BA}_{\mathrm{t}-1}+\mathrm{b}_{2} \mathrm{BA}_{\mathrm{t}-1}+\mathrm{b}_{3} \mathrm{BA} \mathrm{A}_{\mathrm{t}-1}+\mathrm{u}_{\mathrm{t}}
$$

where $r_{t}$ is return on day $t$ and BA is the trade direction of more aggressive orders. We define $B A$ to be 1 if the transaction price is greater than the average of the best bid and ask, and to be -1 if the price is less than the average. When buy orders are more aggressive and are liquidity driven the transaction price will be higher temporarily and then drop. The regression model (10) estimates the price reversal as a function of previous trade directions. If BA captures the direction of liquidity orders, then coefficients b's will be negative; If BA actually captures the direction of orders based on information, then coefficients b's will be zero.

For our sample stocks, we estimate the regression model (10) for each stock. The medians of the estimated coefficients on the variables $B A$ are all negative: $-0.304,-0.050$, and -0.009 . The negative coefficients on $B A$ means that the expected future return is negative when the current buy orders exceed sell orders $(B A=1)$. We use the standard deviation of the fitted price reversals of the regression (10) to estimate the trading friction. The median of the estimated trading friction across all stocks is $0.31 \%$.

In Taiwan, investors also have pay commissions and the securities transaction tax. The two-way commission is $0.285 \%$. The securities transactions tax $0.3 \%$ is paid only by the seller. Adding commissions, the securities transaction tax, and trading friction gives us the estimated 
two-way transaction cost in Taiwan: $0.895 \%$. 


\section{References}

Altken M. J., A. Frino, M S. McCorry and P. L. Swan, 1998, Short Sales Are Almost Instantaneously Bad News: Evidence from the Australian Stock Exchange, Journal of Finance 53, 2205-2223.

Avramov, D., T. Chordia, and A. Goyal, 2006, Liquidity and Autocorrelations in Individual Stock Returns, Journal of Finance 61, 2365-2394.

Andrade, S. C., C. Chang, and M. S. Seasholes, 2008, Trading Imbalances, Predictable Reversals, and Cross-Stock Price Pressure, Journal of Financial Economics 88, 406-423.

Baker, G. P., and B. J. Hall, 2004, CEO Incentives and Firm Size, Journal of Labor Economics 22, 767-798.

Barber, B. M., Y. Lee, Y. Liu, and T. Odean, forthcoming, Just how much do individual investors lose by trading? Review of Financial Studies.

Bessembinder, H., and M. G. Hertzel, 1993, Return autocorrelations around nontrading days, Review of Financial Studies 6, 155-189.

Brown, P., D. Walsh, and A. Yuen, 1997, The interaction between order imbalance and stock price, Pacific-Basin Finance Journal 5, 539-557.

Campbell, J. Y., S. J. Grossman, and J. Wang, 1993, Trading volume and serial correlation in stock returns, Quarterly Journal of Economics 108, 905-940.

Chan, K., W., and M. Fong, 2000, Trade size, order imbalance, and the volatility-volume relation, Journal of Financial Economics 57, 247-273.

Chang, E. C., J. W. Cheng, and Y. Yu, 2007, Short-Sales Constraints and Price Discovery: Evidence from the Hong Kong Market, Journal of Finance 62, 2097-2121.

Chen, J., H. Hong and J. Stein, 2001, Forecasting Crashes: Trading Volume, Past Returns, and Conditional Skewness in Stock Prices, Journal of Financial Economics 61, 345-381. 
Chordia T., R. Roll, and A. Subrahmanyam, 2002, Order imbalance, liquidity, and market returns, Journal of Financial Economics 65, 111-130.

Chordia T. and A. Subrahmanyam, 2004, Order imbalance and individual stock returns: Theory and evidence, Journal of Financial Economics 72, 485-518.

Conrad, J.S., A. Hameed, and C. Niden, 1994, Volume and autocovariances in short-horizon individual security returns, Journal of Finance 49, 1305-1329.

Dechow, P., A. Hutton, L. Meulbroek, and R. Sloan, 2001, Short-Sellers, Fundamental Analysis and Stock Returns, Journal of Financial Economics 61, 77-106.

Falkenstein, E.G., 1996, Preferences for stock characteristics as revealed by mutual fund portfolio holdings, Journal of Finance 51, 111-135.

Figlewski, S., 1981, The Informational Effects of Restrictions on Short Sales: Some Empirical Evidence, Journal of Financial and Quantitative Analysis 4, 463-476.

Hirshleifer, D., A. Subrahmanyam, and S. Titman, 1994, Security analysis and trading patterns when some investors receive information before others, Journal of Finance 49, 1665-1698.

Hong, H. and J. Stein, 2002, Differences of opinion, short-sales constraints and market crashes, Review of Financial Studies 16, 487-525.

Jones, M. C., and O. A. Lamont, 2002, Short-Sale Constraints and Stock Returns, Journal of Financial Economics 66(2-3), 207-239.

Jorion, Philippe, 1990, The Exchange-Rate Exposure of U.S. Multinationals, The Journal of Business 63, pp. 331-345

Kang, J.-K., and R.M. Stulz, 1997, Why is there a home bias? An analysis of foreign portfolio equity ownership in Japan, Journal of Financial Economics 46, 3-28.

Kyle, A., 1985, Continuous auctions and insider trading, Econometrica 53, 1315-1335. 
Lee, Y., Y. Liu, R. Roll and A. Subrahmany, 2004, Order Imbalance and Market Efficiency: Evidence from the Taiwan Stock Exchange, Journal of Financial and Quantitative Analysis 39, 327-342.

Li, G., "Robust Regression,” in Exploring Data Tables, Trends and Shapes, edited by D.C. Hoaglin, F. Mosteller and J. W. Tukey, John Wiley and Sons, 1985.

Llorente, G., R. Michaely, G. Saar, and J. Wang, 2002, Dynamic volume-return relation of individual stocks, Review of Financial Studies 15, 1005-1048.

Morse, D., 1980, Asymmetrical information in securities markets and trading volume, Journal of Financial and Quantitative Analysis 15, 1129-1148.

Sias, R. W. and L. T. Starks, 1997, Return autocorrelation and institutional investors, Journal of Financial Economics 46, 103-131.

Yan, X. S., and Z. Zhang, forthcoming, Institutional Investors and Equity Returns: Are Short-term Institutions Better Informed? Review of Financial Studies. 


\section{Table 1. Summary statistics}

For each stock, we estimate statistics using its time-series data. Then we compute the quartiles of these statistics across stocks. Turnover is the number of total shares traded divided by the number of shares outstanding, and buy turnover is the shares bought divided by the number of shares outstanding. The sample includes 1,049 stocks for which there are at least 750 daily observations and that were listed on the Taiwan Stock Exchange and the Gre Tai Securities Market. The sample period is from 2000/12/12 to 2007/3/30.

\begin{tabular}{|c|c|c|c|c|}
\hline Variable & Statistics & Quartile1 & Median & Quartile3 \\
\hline $\begin{array}{l}\text { Market Capitalization } \\
\text { (NT\$ Million) }\end{array}$ & Mean & 1045.9 & 2555.2 & 6755.5 \\
\hline \multirow{3}{*}{$\begin{array}{l}\text { Return } \\
(\%)\end{array}$} & Mean & 0.0360 & 0.0761 & 0.1229 \\
\hline & Standard Deviation & 2.2733 & 2.6876 & 3.0774 \\
\hline & $1^{\text {st }}$ autocorrelation coefficient. & 0.0344 & 0.0824 & 0.1330 \\
\hline \multirow{3}{*}{ Detrended log turnover } & Mean & -0.0382 & 0.0199 & 0.0788 \\
\hline & Standard deviation & 0.8943 & 1.0299 & 1.2259 \\
\hline & $1^{\text {st }}$ autocorrelation coefficient. & 0.6359 & 0.7251 & 0.7758 \\
\hline \multirow{5}{*}{$\begin{array}{c}\text { Buy } \\
\text { Turnover of Foreigners } \\
(\%)\end{array}$} & Mean & 0.0015 & 0.0083 & 0.0317 \\
\hline & Standard deviation & 0.0138 & 0.0540 & 0.1215 \\
\hline & 1st autocorrelation coefficient. & 0.0935 & 0.2573 & 0.4049 \\
\hline & Non-zero volume days (\%) & 3.75 & 13.61 & 37.40 \\
\hline & Large buy days (\%) & 22.27 & 25.22 & 32.56 \\
\hline \multirow{5}{*}{$\begin{array}{c}\text { Buy } \\
\text { Turnover of Mutual } \\
\text { Funds } \\
\text { (\%) }\end{array}$} & Mean & 0.0007 & 0.0077 & 0.0297 \\
\hline & Standard deviation & 0.0109 & 0.0520 & 0.1231 \\
\hline & 1st autocorrelation coefficient. & 0.2411 & 0.3630 & 0.4519 \\
\hline & Non-zero volume days (\%) & 0.66 & 6.21 & 22.27 \\
\hline & Large buy days (\%) & 18.71 & 22.63 & 28.73 \\
\hline \multirow{5}{*}{$\begin{array}{c}\text { Buy Turnover of } \\
\text { Domestic Dealers (\%) }\end{array}$} & Mean & 0.0009 & 0.0050 & 0.0164 \\
\hline & Standard deviation & 0.0097 & 0.0308 & 0.0639 \\
\hline & 1st autocorrelation coefficient. & 0.1486 & 0.2797 & 0.3911 \\
\hline & Non-zero volume days (\%) & 3.45 & 18.79 & 37.74 \\
\hline & Large buy days (\%) & 22.43 & 25.86 & 31.56 \\
\hline
\end{tabular}




\section{Table 2. Autocorrelation as a function of dummy variables constructed from buy and sell volume from institutional investors}

We perform the following time-series regression for each stock.

$R_{t+1}=C_{0}+C_{l} R_{t}+C_{2} V_{t} R_{t}+C_{F B} D_{t}^{F B} D_{t[R>0]} V_{t} R_{t}+C_{F S} D_{t}^{F S} D_{t[R \leqq 0]} V_{t} R_{t}+C_{M B} D_{t}^{M B} D_{t[R>0]} V_{t} R_{t}+C_{M S} D_{t}^{M S} D_{t[R \leqq 0]} V_{t} R_{t}+$ $C_{D B} D_{t}^{D B} D_{t[R>0]} V_{t} R_{t}+C_{D S} D_{t}^{D S} D_{t[R \leqq 0]} V_{t} R_{t}+\varepsilon_{t+1}$,

where $V_{t}$ is the detrended log of total turnover; $D_{t[R>0]}=1$ if $R_{t}>0$ and 0 otherwise, $D_{t[R \leqq 0]}=1$ if $R_{t} \leqq 0$ and 0 otherwise; $D_{t}^{F B}=1$ if the buy turnover (B) of foreigners $(\mathrm{F})$ is higher than its past-200-days average, and $D_{t}^{F B}=0$ otherwise. $D_{t}^{F S}, D_{t}^{M B}, D_{t}^{M S}, D_{t}^{D B}$, and $D_{t}^{D S}$ are similarly defined, where superscript S denotes sell turnover, M denotes mutual fund, and D denotes dealers. The sample includes 1,049 stocks for which there are at least 750 daily observations and that were listed on the Taiwan Stock Exchange and the Gre Tai Securities Market. The sample period is from 2000/12/12 to 2007/3/30. From the time-series regression estimates, we calculate and report the cross-sectional robust mean for each size group. * denotes significance at the $10 \%$ level, ** denotes significance at the 5\% level, and *** denotes significance at the $1 \%$ level.

Panel A. Average coefficients across stocks

\begin{tabular}{|c|c|c|c|}
\hline & Robust Regression & $\begin{array}{c}\text { Trimming at the } 5^{\text {th }} \text { and } \\
95^{\text {th }} \text { percentiles }\end{array}$ & $\begin{array}{c}\text { Winsorizing at the } 5^{\text {th }} \\
\text { and } 95^{\text {th }} \text { percentiles }\end{array}$ \\
\hline$C_{0}$ (Constant) & $0.0768^{* * *}$ & $0.0781^{* * *}$ & $0.0790^{* * *}$ \\
\hline$C_{l}\left(R_{t}\right)$ & $0.0539 * * *$ & $0.0510^{* * *}$ & $0.0502^{* * *}$ \\
\hline$C_{2}\left(V_{t} R_{t}\right)$ & 0.0029 & 0.0017 & 0.0005 \\
\hline$C_{F B}\left(D_{t}^{F B} D_{t[R>0]} V_{t} R_{t}\right)$ & $0.0195^{* * *}$ & $0.0152^{* * *}$ & $0.0120^{* * *}$ \\
\hline$C_{F S}\left(D_{t}^{F S} D_{t[R \leqq 0]} V_{t} R_{t}\right)$ & $0.0245^{* * *}$ & $0.0177^{* * *}$ & $0.0123^{*}$ \\
\hline$C_{M B}\left(D_{t}^{M B} D_{t[R>0]} V_{t} R_{t}\right)$ & $0.0487^{* * *}$ & $0.0419 * * *$ & $0.0369 * * *$ \\
\hline$C_{M S}\left(D_{t}^{M S} D_{t[R \leqq 0]} V_{t} R_{t}\right)$ & -0.0047 & -0.0038 & -0.0001 \\
\hline$C_{D B}\left(D_{t}^{D B} D_{t[R>0]} V_{t} R_{t}\right)$ & $-0.0241^{* * *}$ & $-0.0249 * * *$ & $-0.0247^{* * *}$ \\
\hline$C_{D S}\left(D_{t}^{D S} D_{t[R \leqq 0]} V_{t} R_{t}\right)$ & $-0.0129^{*}$ & $-0.0160^{* * *}$ & $-0.0171^{* * *}$ \\
\hline $\mathrm{TEST}: C_{F B}>C_{F S}$ & -0.0031 & -0.0036 & -0.0003 \\
\hline $\mathrm{TEST}: C_{M B}>C_{M S}$ & $0.0408^{* * *}$ & $0.0450^{* * *}$ & $0.0354^{* * *}$ \\
\hline $\mathrm{TEST}: C_{D B}>C_{D S}$ & -0.0090 & $-0.0126^{*}$ & -0.0078 \\
\hline
\end{tabular}


Panel B. Average coefficients across stocks within each size quartile

\begin{tabular}{|c|c|c|c|c|}
\hline & $\begin{array}{c}1^{\text {st }} \text { Quartile } \\
\text { The Smallest }\end{array}$ & $2^{\text {nd }}$ Quartile & $3^{\text {rd }}$ Quartile & $\begin{array}{c}4^{\text {th }} \text { Quartile } \\
\text { The Largest }\end{array}$ \\
\hline$C_{0}$ (Constant) & $0.0456^{* * *}$ & $0.0774^{* * *}$ & $0.0868^{* * *}$ & $0.0923^{* * *}$ \\
\hline$C_{l}\left(R_{t}\right)$ & $0.0340^{* * *}$ & $0.0607^{* * *}$ & $0.0652^{* * *}$ & $0.0444^{* * *}$ \\
\hline$C_{2}\left(V_{t} R_{t}\right)$ & $0.0513^{* * *}$ & $0.0172^{* * *}$ & $-0.0164^{* * *}$ & $-0.0493^{* * *}$ \\
\hline$C_{F B}\left(D_{t}^{F B} D_{t[R>0]} V_{t} R_{t}\right)$ & $-0.0323^{* *}$ & -0.0068 & $0.0236^{* * *}$ & $0.0608^{* * *}$ \\
\hline$C_{F S}\left(D_{t}^{F S} D_{t[R \leq 0]} V_{t} R_{t}\right)$ & 0.0084 & 0.0020 & $0.0345^{* * *}$ & $0.0396^{* * *}$ \\
\hline$C_{M B}\left(D_{t}^{M B} D_{t[R>0]} V_{t} R_{t}\right)$ & 0.0163 & $0.0420^{* * *}$ & $0.0542^{* * *}$ & $0.0488^{* * *}$ \\
\hline$C_{M S}\left(D_{t}^{M S} D_{t[R \leq 0]} V_{t} R_{t}\right)$ & -0.0381 & 0.0093 & 0.0121 & $-0.0217^{*}$ \\
\hline$C_{D B}\left(D_{t}^{D B} D_{t[R>0]} V_{t} R_{t}\right)$ & $-0.0443^{* * *}$ & $-0.0349 * *$ & $-0.0129 *$ & $-0.0201^{* * *}$ \\
\hline$C_{D S}\left(D_{t}^{D S} D_{t[R \leq 0]} V_{t} R_{t}\right)$ & $-0.0476^{* *}$ & -0.0009 & $-0.0258^{* *}$ & 0.0037 \\
\hline TEST: $C_{F B}>C_{F S}$ & -0.0364 & -0.0097 & -0.0043 & $0.0202^{*}$ \\
\hline TEST: $C_{M B}>C_{M S}$ & 0.0306 & 0.0170 & $0.0445^{* * *}$ & $0.0673^{* * *}$ \\
\hline TEST: $C_{D B}>C_{D S}$ & -0.0123 & -0.0237 & 0.0156 & $-0.0229^{*}$ \\
\hline
\end{tabular}




\section{Table 3. Autocorrelation as a function of buy and sell volume from institutional investors}

We perform the following time-series regression for each stock.

$R_{t+1}=C_{0}+C_{1} R_{t}+C_{2} V_{t}^{O} R_{t}+C_{F B} Q_{t}^{F B} D_{t[R>0]} R_{t}+C_{F S} Q_{t}^{F S} D_{t[R \leqq 0]} R_{t}+C_{M B} Q_{t}^{M B} D_{t[R>0]} R_{t}+C_{M S} Q_{t}^{M S} D_{t[R \leqq 0]} R_{t}+$ $C_{D B} Q_{t}^{D B} D_{t[R>0]} R_{t}+C_{D S} Q_{t}^{D S} D_{t[R \leqq 0]} R_{t}+\varepsilon_{t+1 .}$,

where $V_{i t}{ }^{O}$ is defined as $\ln \left(\right.$ turnover $\left._{i t}{ }^{O}+0.00000255\right)$ and is detrended by its past-200-days average. $D_{t[R>0]}=1$ if $R_{i t}>0$ and 0 otherwise, $D_{t[R \leqq 0]}=1$ if $R_{i t} \leqq 0$ and 0 otherwise. $Q_{i t}{ }^{F B}=$ turnover $_{t}^{F B} /$ turnover $_{t}^{O}$ and is detrended by its past-200-days average. $Q_{i t}{ }^{F S}, Q_{i t}{ }^{M B}, Q_{i t}{ }^{M S}, Q_{i t}{ }^{D B}$, and $Q_{i t}{ }^{D S}$ are similarly defined. The sample includes 1,049 stocks for which there are at least 750 observations and that were listed on the Taiwan Stock Exchange and the Gre Tai Securities Market. The sample period is from 2000/12/12 to 2007/3/30. From the time-series regression estimates, we calculate and report the cross-sectional robust mean for each size group. * denotes significance at the $10 \%$ level, ** denotes significance at the $5 \%$ level, and *** denotes significance at the $1 \%$ level.

\begin{tabular}{|c|c|c|c|c|c|}
\hline & All firms & $\begin{array}{l}1^{\text {st }} \text { Quartile } \\
\text { The Smallest }\end{array}$ & $2^{\text {nd }}$ Quartile & $3^{\text {rd }}$ Quartile & $\begin{array}{l}4^{\text {th }} \text { Quartile } \\
\text { The Largest }\end{array}$ \\
\hline$C_{0}$ (Constant) & $0.0781^{* * *}$ & $0.0482 * * *$ & $0.0742 * * *$ & $0.0884 * * *$ & $0.0975^{* * *}$ \\
\hline$C_{l}\left(R_{t}\right)$ & $0.0532 * * *$ & $0.0312 * * *$ & $0.0597 * * *$ & $0.0650 * * *$ & $0.0431 * * *$ \\
\hline$C_{2}\left(V_{t}^{O} R_{t}\right)$ & $0.0125^{* * *}$ & $0.0497 * * *$ & $0.0171 * * *$ & -0.0021 & $-0.0123^{* * *}$ \\
\hline$C_{F B}\left(\mathrm{Q}_{t}^{F B} D_{t[R>0]} R_{t}\right)$ & $0.2108 * * *$ & -0.0571 & $0.3003 * * *$ & $0.2825 * * *$ & $0.1074 * * *$ \\
\hline$C_{F S}\left(Q_{t}^{F S} D_{t[R \leqq 0]} R_{t}\right)$ & -0.0193 & -0.2105 & $-0.2000 * * *$ & -0.0320 & $0.0531^{* * *}$ \\
\hline$C_{M B}\left(Q_{t}^{M B} D_{t[R>0]} R_{t}\right)$ & $0.4101^{* * *}$ & 0.2257 & $0.3176^{* * *}$ & $0.5033 * * *$ & $0.3342 * * *$ \\
\hline$C_{M S}\left(Q_{t}^{M S} D_{t[R \leqq 0]} R_{t}\right)$ & $0.1283^{* * *}$ & $0.3296^{*}$ & $0.1281^{* *}$ & $0.0767 *$ & $0.1162^{* * *}$ \\
\hline$C_{D B}\left(Q_{t}^{D B} D_{t[R>0]} R_{t}\right)$ & $-0.1997 * * *$ & -0.4374 & -0.2335 & -0.0909 & $-0.2569 * * *$ \\
\hline$C_{D S}\left(Q_{t}^{D S} D_{t[R \leqq 0]} R_{t}\right)$ & $-0.1118 * * *$ & 0.0897 & -0.0122 & $-0.1295 *$ & $-0.2290 * * *$ \\
\hline TEST: $C_{F B}>C_{F S}$ & $0.1761^{* * *}$ & 0.8303 & $0.3253^{* *}$ & $0.2551^{* * *}$ & 0.0336 \\
\hline TEST: $C_{M B}>C_{M S}$ & $0.3266^{* * *}$ & -0.0707 & $0.3431^{* * *}$ & $0.4155^{* * *}$ & $0.2285^{* * *}$ \\
\hline TEST: $C_{D B}>C_{D S}$ & -0.0647 & -0.3206 & -0.2303 & 0.1216 & -0.0916 \\
\hline
\end{tabular}




\section{Table 4. Autocorrelation of firm-specific returns and volumes}

We perform the following time-series regression for each stock.

$R_{t+1}=C_{0}+C_{l} R_{t}+C_{2} V_{t} R_{t}+C_{F B} D_{t}^{F B} D_{t[R>0]} V_{t} R_{t}+C_{F S} D_{t}^{F S} D_{t[R \leq 0]} V_{t} R_{t}+C_{M B} D_{t}^{M B} D_{t[R>0]} V_{t} R_{t}+C_{M S} D_{t}^{M S} D_{t[R \leq 0]} V_{t} R_{t}+$ $C_{D B} D_{t}^{D B} D_{t[R>0]} V_{t} R_{t}+C_{D S} D_{t}^{D S} D_{t[R \leq 0]} V_{t} R_{t}+C_{Z} D_{t}^{Z} D_{t[R>0]} V_{t} R_{t}+\varepsilon_{t+1,}$,

where $V_{i t}$ is defined as $\ln \left(\right.$ turnover $\left._{i t}+0.00000255\right)$ and is detrended by its past-200-days average. $D_{t[R>0]}=1$ if $R_{i t}>0$ and 0 otherwise, $D_{t[R \leq 0]}=1$ if $R_{i t} \leqq 0$ and 0 otherwise; $D_{i t}{ }^{F B}=1$ if $V_{i t}{ }^{F B}$ is higher than its past-200-days average, and $D_{i t}{ }^{F B}=0$ otherwise. $D_{i t}{ }^{F S}, D_{i t}{ }^{M B}, D_{i t}{ }^{M S}, D_{i t}{ }^{D B}$, and $D_{i t}{ }^{D S}$ are similarly defined. $V_{i t}{ }^{F B}\left(V_{i t}^{F S}\right), V_{i t}{ }^{M B}\left(V_{i t}{ }^{M S}\right)$, and $V_{i t}^{D B}\left(V_{i t}^{D S}\right)$ are the daily buy (sell) turnover of foreigner, mutual fund, and dealers trading, respectively. $M R_{t+1}$ is the market return, and $I R_{t+1}$ is the industry return. The sample includes 1,049 stocks for which there are at least 750 daily observations and that were listed on the Taiwan Stock Exchange and the Gre Tai Securities Market. The sample period is from 2000/12/12 to 2007/3/30. From the time-series regression estimates, we calculate and report the cross-sectional robust mean for each size group. * denotes significance at the $10 \%$ level, $* *$ denotes significance at the $5 \%$ level, and $* * *$ denotes significance at the $1 \%$ level.

\begin{tabular}{|c|c|c|c|}
\hline & $(1)$ & $(2)$ & $(3)$ \\
\hline$C_{0}($ Constant $)$ & $0.0279^{* * *}$ & $-0.0087^{* * *}$ & $-0.0109^{* * *}$ \\
\hline$C_{l}\left(R_{t}\right)$ & $0.0486^{* * *}$ & $0.0484^{* * *}$ & $0.0473^{* * *}$ \\
\hline$C_{2}\left(V_{t} R_{t}\right)$ & $0.0142^{* * *}$ & $0.0127^{* * *}$ & $0.0059^{* *}$ \\
\hline$C_{F B}\left(D_{t}^{F B} D_{t[R>0]} V_{t} R_{t}\right)$ & $0.0136^{* * *}$ & $0.0183^{* * *}$ & $0.0195^{* * *}$ \\
\hline$C_{F S}\left(D_{t}^{F S} D_{t[R \leqq 0]} V_{t} R_{t}\right)$ & $0.0137^{* *}$ & $0.0207^{* * *}$ & $0.0158^{* * *}$ \\
\hline$C_{M B}\left(D_{t}^{M B} D_{t[R>0]} V_{t} R_{t}\right)$ & $0.0406^{* * *}$ & $0.0402^{* * *}$ & $0.0295^{* * *}$ \\
\hline$C_{M S}\left(D_{t}^{M S} D_{t[R \leq 0]} V_{t} R_{t}\right)$ & 0.0055 & $0.0191^{* *}$ & 0.0048 \\
\hline$C_{D B}\left(D_{t}^{D B} D_{t[R>0]} V_{t} R_{t}\right)$ & $-0.0300^{* * *}$ & $-0.0319^{* * *}$ & $-0.0140^{* * *}$ \\
\hline$C_{D S}\left(D_{t}^{D S} D_{t[R \leq 0]} V_{t} R_{t}\right)$ & $-0.0108^{*}$ & -0.0097 & $-0.0096^{*}$ \\
\hline$C_{6}\left(M R_{t+1}\right)$ & $0.1284^{* * *}$ & & \\
\hline$C_{7}\left(I R_{t+1}\right)$ & $0.6615^{* * *}$ & & \\
\hline Remove market component from return & NO & YES & YES \\
\hline Remove market component from total turnover & NO & YES & YES \\
\hline Remove market component from institutional & NO & NO & YES \\
\hline turnover & & & \\
\hline
\end{tabular}




\section{Table 5. Autocorrelation as a function of contemporaneous trading}

We perform the following time-series regression for each stock.

$R_{t+1}=C_{0}+C_{l} R_{t}+C_{2} V_{t} R_{t}+\left(C_{F B}+C_{F B B} D_{t+1}^{F B}+C_{F B S} D_{t+1}^{F S}\right) D_{t}^{F B} D_{t[R>0]} V_{t} R_{t}+\left(C_{F S}+C_{F S S} D_{t+1}^{F S}+C_{F S B} D_{t+1}^{F B}\right) D_{t}^{F S}$ $D_{t[R \leqq 0]} V_{t} R_{t}+\left(C_{M B}+C_{M B B} D_{t+1}^{M B}+C_{M B S} D_{t+1}^{M S}\right) D_{t}^{M B} D_{t[R>0]} V_{t} R_{t}+\left(C_{M S}+C_{M S S} D_{t+1}{ }^{M S}+C_{M S B} D_{t+1}^{M B}\right) D_{t}^{M S} D_{t[R \leq 0]} V_{t}$ $R_{t}+C_{D B} D_{t}^{D B} D_{t[R>0]} V_{t} R_{t}+C_{D S} D_{t}^{D S} D_{t[R \leq 0]} V_{t} R_{t}+\varepsilon_{t+1}$.

where $V_{i t}$ is defined as $\ln \left(\right.$ turnover $\left._{i t}+0.00000255\right)$ and is detrended by its past-200-days average. $D_{t[R>0]}=1$ if $R_{i t}>0$ and 0 otherwise, $D_{t[R \leqq 0]}=1$ if $R_{i t} \leqq 0$ and 0 otherwise; $D_{i t}{ }^{F B}=1$ if $V_{i t}{ }^{F B}$ is higher than its past-200-days average, and $D_{i t}{ }^{F B}=0$ otherwise. $D_{i t}{ }^{F S}, D_{i t}{ }^{M B}, D_{i t}{ }^{M S}, D_{i t}{ }^{D B}$, and $D_{i t}{ }^{D S}$ are similarly defined. $V_{i t}{ }^{F B}\left(V_{i t}{ }^{F S}\right), V_{i t}{ }^{M B}\left(V_{i t}{ }^{M S}\right)$, and $V_{i t}^{D B}\left(V_{i t}^{D S}\right)$ are the daily buy (sell) turnover of foreigner, mutual fund, and dealers trading, respectively. The sample includes 1,049 stocks for which there are at least 750 daily observations and that were listed on the Taiwan Stock Exchange and the Gre Tai Securities Market. The sample period is from 2000/12/12 to 2007/3/30. From the time-series regression estimates, we calculate and report the cross-sectional robust mean for each size group. ${ }^{*}$ denotes significance at the $10 \%$ level, ${ }^{* *}$ denotes significance at the $5 \%$ level, and ${ }^{* * *}$ denotes significance at the $1 \%$ level

\begin{tabular}{|c|c|c|c|c|c|}
\hline & All firms & $\begin{array}{c}1^{\text {st }} \text { Quartile } \\
\text { The Smallest }\end{array}$ & $2^{\text {nd }}$ Quartile & $3^{\text {rd }}$ Quartile & $\begin{array}{l}4^{\text {th }} \text { Quartile } \\
\text { The Largest }\end{array}$ \\
\hline$C_{0}$ (Constant) & $0.0778^{* * *}$ & $0.0460 * * *$ & $0.0765^{* * *}$ & $0.0873^{* * *}$ & $0.0966^{* * *}$ \\
\hline$C_{l}\left(R_{t}\right)$ & $0.0541^{* * *}$ & $0.0335^{* * *}$ & $0.0609 * * *$ & $0.0651^{* * *}$ & $0.0454 * * *$ \\
\hline$C_{2}\left(V_{t} R_{t}\right)$ & 0.0024 & $0.0519 * * *$ & $0.0168 * * *$ & $-0.0167 * * *$ & $-0.0519 * * *$ \\
\hline$C_{F B}\left(D_{t}^{F B} D_{t[R>0]} V_{t} R_{t}\right)$ & $-0.0319 * * *$ & -0.0333 & $-0.0370 * * *$ & -0.0168 & $-0.0404 * * *$ \\
\hline$C_{F B B}\left(D_{t}^{F B} D_{t+1}^{F B} D_{t[R>0]} V_{t} R_{t}\right)$ & $0.0992 * * *$ & -0.0071 & $0.0531^{* *}$ & $0.0798^{* * *}$ & $0.1710^{* * *}$ \\
\hline$C_{F B S}\left(D_{t}^{F B} D_{t+1}^{F S} D_{t[R>0]} V_{t} R_{t}\right)$ & 0.0137 & 0.0063 & -0.0157 & $0.0332 * *$ & 0.0026 \\
\hline$C_{F S}\left(D_{t}^{F S} D_{t[R \leqq 0]} V_{t} R_{t}\right)$ & $0.0214^{* *}$ & -0.0168 & 0.0163 & $0.0296 *$ & 0.0303* \\
\hline$C_{F S S}\left(D_{t}^{F S} D_{t+1}^{F S} D_{t[R \leqq 0]} V_{t} R_{t}\right)$ & $0.0337 * *$ & 0.0043 & -0.0194 & -0.0039 & $0.1029 * * *$ \\
\hline$C_{F S B}\left(D_{t}^{F S} D_{t+1}^{F B} D_{t[R \leqq 0]} V_{t} R_{t}\right)$ & $-0.0841^{* * *}$ & $-0.2983^{* *}$ & -0.0383 & -0.0211 & $-0.1329 * * *$ \\
\hline$C_{M B}\left(D_{t}^{M B} D_{t[R>0]} V_{t} R_{t}\right)$ & $-0.0447 * * *$ & 0.0201 & $-0.0372^{*}$ & $-0.0286 * *$ & $-0.0735 * * *$ \\
\hline$C_{M B B}\left(D_{t}^{M B} D_{t+1}^{M B} D_{t[R>0]} V_{t} R_{t}\right)$ & $0.1662^{* * *}$ & 0.0004 & $0.1332^{* * *}$ & $0.1625^{* * *}$ & $0.2155^{* * *}$ \\
\hline$C_{M B S}\left(D_{t}^{M B} D_{t+1}^{M S} D_{t[R>0]} V_{t} R_{t}\right)$ & $-0.0707 * * *$ & -0.0481 & $-0.1308^{* * *}$ & $-0.0779 * * *$ & $-0.0591^{* * *}$ \\
\hline$C_{M S}\left(D_{t}^{M S} D_{t[R \leqq 0]} V_{t} R_{t}\right)$ & $-0.0285^{* *}$ & 0.0035 & -0.0501 & -0.0091 & $-0.0356 * *$ \\
\hline$C_{M S S}\left(D_{t}^{M S} D_{t+1}{ }^{M S} D_{t[R \leqq 0]} V_{t} R_{t}\right)$ & $0.1054^{* * *}$ & 0.0142 & $0.1284^{* * *}$ & $0.0988^{* * *}$ & $0.1238 * * *$ \\
\hline$C_{M S B}\left(D_{t}^{M S} D_{t+1}^{M B} D_{t[R \leqq 0]} V_{t} R_{t}\right)$ & $-0.1995 * * *$ & 0.0955 & -0.1076 & $-0.2061^{* * *}$ & $-0.2192 * * *$ \\
\hline$C_{D B}\left(D_{t}^{D B} D_{[R>0]} V_{t} R_{t}\right)$ & $-0.0284^{* * *}$ & $-0.0512 * * *$ & $-0.0369 * * *$ & $-0.0146^{* *}$ & $-0.0287^{* * *}$ \\
\hline$C_{D S}\left(D_{t}^{D S} D_{[R \leqq 0]} V_{t} R_{t}\right)$ & $-0.0127 *$ & $-0.0465^{* *}$ & -0.0073 & $-0.0249 * *$ & 0.0096 \\
\hline
\end{tabular}




\section{Table 6. Measurement interval depends on turnover}

We perform the following time-series regression for each stock.

$R_{t+1}=C_{0}+C_{l} R_{t}+C_{2} V_{t} R_{t}+C_{F B} D_{t}^{F B} D_{t[R>0]} V_{t} R_{t}+C_{F S} D_{t}^{F S} D_{t[R \leq 0]} V_{t} R_{t}+C_{M B} D_{t}^{M B} D_{t[R>0]} V_{t} R_{t}+C_{M S} D_{t}^{M S} D_{t[R \leq 0]} V_{t} R_{t}+$ $C_{D B} D_{t}^{D B} D_{t[R>0]} V_{t} R_{t}+C_{D S} D_{t}^{D S} D_{t[R \leq 0]} V_{t} R_{t}+C_{Z} D_{t}^{Z} D_{t[R>0]} V_{t} R_{t}+\varepsilon_{t+1}$,

where $V_{i t}$ is defined as $\ln \left(\right.$ turnover $\left._{i t}+0.00000255\right)$ and is detrended by its past-200-days average. $D_{t[R>0]}=1$ if $R_{i t}>0$ and 0 otherwise, $D_{t[R \leqq 0]}=1$ if $R_{i t} \leqq 0$ and 0 otherwise; $D_{i t}{ }^{F B}=1$ if $V_{i t}{ }^{F B}$ is higher than its past-200-days average, and $D_{i t}^{F B}=0$ otherwise. $D_{i t}^{F S}, D_{i t}^{M B}, D_{i t}^{M S}, D_{i t}^{D B}$, and $D_{i t}{ }^{D S}$ are similarly defined. $V_{i t}^{F B}\left(V_{i t}^{F S}\right), V_{i t}^{M B}\left(V_{i t}^{M S}\right)$, and $V_{i t}^{D B}\left(V_{i t}^{D S}\right)$ are the daily buy (sell) turnover of foreigner, mutual fund, and dealers trading, respectively. The sample includes 1,049 stocks for which there are at least 750 daily observations and that were listed on the Taiwan Stock Exchange and the Gre Tai Securities Market. The sample period is from 2000/12/12 to 2007/3/30. From the time-series regression estimates, we calculate and report the cross-sectional robust mean for each size group. * denotes significance at the $10 \%$ level, ${ }^{* *}$ denotes significance at the $5 \%$ level, and ${ }^{* * *}$ denotes significance at the $1 \%$ level

We calculate the median daily turnover for each stock over the sample period (MedTurn) and assign all stocks into three groups according to their median turnover. The cross-sectional averages of MedTurn for the three groups are $0.1060 \%, 0.3615 \%$, and $1.0414 \%$, respectively. The cross-sectional medians of MedTurn for the three groups are $0.1058 \%, 0.3507 \%$, and $0.9011 \%$, respectively. We use the one-day interval for the high MedTurn stocks (350 stocks), the three-day interval for the median MedTurn stocks (349 stocks), and the eight-day interval for the low MedTurn stocks (350 stocks).

\begin{tabular}{|c|l|l|l|l|c|}
\hline & \multicolumn{1}{|c|}{ All firms } & $\begin{array}{c}1^{\text {st }} \text { Quartile } \\
\text { The Smallest }\end{array}$ & $2^{\text {nd }}$ Quartile & $3^{\text {rd }}$ Quartile & $\begin{array}{c}4^{\text {th }} \text { Quartile } \\
\text { The Largest }\end{array}$ \\
\hline$C_{0}$ (Constant) & $0.2254^{* * *}$ & $0.3368^{* * *}$ & $0.2477^{* * *}$ & $0.1550^{* * *}$ & $0.1992^{* * *}$ \\
\hline$C_{l}\left(R_{t}\right)$ & $0.0502^{* * *}$ & $0.0441^{* * *}$ & $0.0534^{* * *}$ & $0.0711^{* * *}$ & $0.0306^{* * *}$ \\
\hline$C_{2}\left(V_{t} R_{t}\right)$ & $-0.0245^{* * *}$ & -0.0087 & $-0.0176^{* * *}$ & $-0.0344^{* * *}$ & $-0.0371^{* * *}$ \\
\hline$C_{F B}\left(D_{t}^{F B} D_{t[R>0]} V_{t} R_{t}\right)$ & 0.0033 & $-0.0432^{* *}$ & $-0.0227 * *$ & 0.0110 & $0.0389 * * *$ \\
\hline$C_{F S}\left(D_{t}^{F S} D_{t[R \leqq 0]} V_{t} R_{t}\right)$ & -0.0155 & -0.0575 & 0.0056 & -0.0128 & -0.0157 \\
\hline$C_{M B}\left(D_{t}^{M B} D_{t[R>0]} V_{t} R_{t}\right)$ & $0.0246^{* * *}$ & -0.0093 & 0.0139 & $0.0418^{* * *}$ & $0.0300^{* *}$ \\
\hline$C_{M S}\left(D_{t}^{M S} D_{t[R \leq 0]} V_{t} R_{t}\right)$ & 0.0106 & -0.0708 & 0.0279 & 0.0271 & -0.0056 \\
\hline$C_{D B}\left(D_{t}^{D B} D_{t[R>0]} V_{t} R_{t}\right)$ & $-0.0224^{* * *}$ & $-0.0500^{* *}$ & $-0.0357 * * *$ & 0.0004 & $-0.0261^{* *}$ \\
\hline$C_{D S}\left(D_{t}^{D S} D_{t[R \leq 0]} V_{t} R_{t}\right)$ & -0.0062 & -0.0341 & 0.0147 & -0.0113 & -0.0052 \\
\hline
\end{tabular}




\section{Table 7. The autocorrelation coefficients when covered warrants contracts exist}

We perform the following time-series regression for each stock.

$R_{t+1}=C_{0}+C_{l} R_{t}+C_{2} V_{t} R_{t}+C_{F B} D_{t}^{F B} D_{t[R>0]} V_{t} R_{t}+C_{F S} D_{t}^{F S} D_{t[R \leq 0]} V_{t} R_{t}+C_{M B} D_{t}^{M B} D_{t[R>0]} V_{t} R_{t}+C_{M S} D_{t}^{M S} D_{t[R \leq 0]} V_{t} R_{t}+$ $C_{D B} D_{t}^{D B} D_{t[R>0]} V_{t} R_{t}+C_{D S} D_{t}^{D S} D_{t[R \leq 0]} V_{t} R_{t}+C_{Z} D_{t}^{Z} D_{t[R>0]} V_{t} R_{t}+\varepsilon_{t+1,}$,

Where $V_{i t}$ is defined as $\ln \left(\right.$ turnover $\left._{i t}+0.00000255\right)$ and is detrended by its past-200-days average. $D_{t[R>0]}=1$ if $R_{i t}>0$ and 0 otherwise, $D_{t[R \leqq 0]}=1$ if $R_{i t} \leqq 0$ and 0 otherwise; $D_{i t}{ }^{F B}=1$ if $V_{i t}{ }^{F B}$ is higher than its past-200-days average, and $D_{i t}{ }^{F B}=0$ otherwise. $D_{i t}{ }^{F S}, D_{i t}{ }^{M B}, D_{i t}{ }^{M S}, D_{i t}{ }^{D B}$, and $D_{i t}{ }^{D S}$ are similarly defined. $V_{i t}{ }^{F B}\left(V_{i t}{ }^{F S}\right), V_{i t}{ }^{M B}\left(V_{i t}{ }^{M S}\right)$, and $V_{i t}^{D B}\left(V_{i t}^{D S}\right)$ are the daily buy (sell) turnover of foreigner, mutual fund, and dealers trading, respectively. The sample includes stocks in the third and fourth size quartile out of 1,049 stocks for which there are at least 750 daily observations and that were listed on the Taiwan Stock Exchange and the Gre Tai Securities Market. The sample period is from 2000/12/12 to 2007/3/30. From the time-series regression estimates, we calculate and report the cross-sectional robust mean separately for stocks that have covered warrants traded on the exchange and for stocks that do not have warrants during the sample period. * denotes significance at the $10 \%$ level, ** denotes significance at the $5 \%$ level, and $* * *$ denotes significance at the $1 \%$ level.

\begin{tabular}{|l|c|c|c|}
\hline & $\begin{array}{c}\text { Stocks with warrant } \\
(1)\end{array}$ & $\begin{array}{c}\text { Stocks without warrant } \\
(2)\end{array}$ & $(1)-(2)$ \\
\hline$C_{F B}\left(D_{t}^{F B} D_{t[R>0]} V_{t} R_{t}\right)$ & $0.0645^{* * *}$ & $0.0233^{* * *}$ & $0.0412^{* * *}$ \\
\hline$C_{F S}\left(D_{t}^{F S} D_{t[R \leqq 0]} V_{t} R_{t}\right)$ & $0.0371^{* * *}$ & $0.0385^{* * *}$ & -0.0014 \\
\hline$C_{M B}\left(D_{t}^{M B} D_{t[R>0]} V_{t} R_{t}\right)$ & $0.0637^{* * *}$ & $0.0391^{* * *}$ & $0.0247^{* *}$ \\
\hline$C_{M S}\left(D_{t}^{M S} D_{t[R \leq 0]} V_{t} R_{t}\right)$ & -0.0119 & 0.0009 & -0.0128 \\
\hline$C_{D B}\left(D_{t}^{D B} D_{t[R>0]} V_{t} R_{t}\right)$ & $-0.0165^{* *}$ & $-0.0165^{* *}$ & 0.0000 \\
\hline$C_{D S}\left(D_{t}^{D S} D_{t[R \leq 0]} V_{t} R_{t}\right)$ & -0.0013 & $-0.0196^{*}$ & 0.0184 \\
\hline
\end{tabular}




\section{Table 8. Daily portfolio return based on lagged returns, aggregate volume, and institutional trading}

We construct three sets of portfolios from stocks which have large daily aggregate volume (turnover is larger than its 200-day moving average). Each set of portfolios includes four portfolios: large buy from institutional investor and positive return on day t, large sell and negative return, small buy and positive return, small sell and positive return; the portfolio composition change daily. The first set of portfolios is based on foreign investors, the second set is based on mutual funds, and the third set is based on dealers. A stock is classified as "large buy (sell)" if the daily buy (sell) turnover is higher than its 200-day moving average, otherwise, it is "small buy (sell)". For each portfolio, we first calculate its daily equally weighted return for day $\mathrm{t}+1$, and then calculate and report its time-series average, $\mathrm{t}$ statistics in parentheses are based on Newey-West standard errors with 10 lagged autocorrelations. The sample includes 1,049 stocks for which there are at least 750 daily observations and that were listed on the Taiwan Stock Exchange and the Gre Tai Securities Market. The sample period is from 2000/12/12 to 2007/3/30.

\begin{tabular}{|c|c|c|c|c|c|c|c|}
\hline $\begin{array}{c}\text { Institutions have } \\
\text { large buy } \\
\text { and } \mathrm{R}_{\mathrm{t}}>0\end{array}$ & $\begin{array}{c}\text { Institutions have } \\
\text { large sell } \\
\text { and } \mathrm{R}_{\mathrm{t}}<0\end{array}$ & $\begin{array}{c}\text { Institutions have } \\
\text { small buy } \\
\text { and } \mathrm{R}_{\mathrm{t}}>0\end{array}$ & $\begin{array}{c}\text { Institutions have } \\
\text { small sell } \\
\text { and } \mathrm{R}_{\mathrm{t}}<0\end{array}$ & \multicolumn{2}{|c|}{$\begin{array}{l}\text { Difference in returns between large and } \\
\text { small trade portfolios }\end{array}$} & \multicolumn{2}{|c|}{ Return of arbitrage portfolios } \\
\hline (1) & (2) & (3) & (4) & $\begin{aligned} & (5) \\
= & (1)-(3)\end{aligned}$ & $\begin{array}{c}(6) \\
=(2)-(4)\end{array}$ & $\begin{array}{c}(7) \\
=(1)-(2)\end{array}$ & $\begin{array}{c}(8) \\
=(3)-(4)\end{array}$ \\
\hline \multicolumn{8}{|c|}{ Panel A. Portfolios based on mutual funds' trading } \\
\hline 0.508 & -0.149 & 0.244 & -0.118 & $0.264^{* * *}$ & -0.031 & $0.657^{* * *}$ & $0.362^{* * *}$ \\
\hline \multicolumn{8}{|c|}{ Panel B. Portfolios based on foreigners' trading } \\
\hline 0.422 & -0.161 & 0.275 & -0.115 & $0.147^{* * *}$ & $-0.046^{* *}$ & $0.583 * * *$ & $0.390 * * *$ \\
\hline \multicolumn{8}{|c|}{ Panel C. Portfolios based on dealers' trading } \\
\hline 0.235 & -0.072 & 0.329 & -0.139 & $-0.094 * * *$ & 0.067 & $0.308 * * *$ & $0.468 * * *$ \\
\hline
\end{tabular}




\section{Table 9. Daily portfolio return based on lagged returns, aggregate volume, institutional trading, and margin trading}

We construct two sets of portfolios from stocks which have large daily total volume (turnover is larger than its 200-day moving average). Each set of portfolios includes six portfolios based on two criteria: the first criteria is based on institutional trade and return (large buy from institutional investor and positive return on day t, large sell and negative return), the second criteria is based on the net margin trading $\left(Z_{i, t}\right)$, which is the daily change in shares held in margin accounts normalized by the number of shares outstanding (Andrade, Chang, and Seasholes, forthcoming). the portfolio composition change daily. In Panel A, each day we sort the stocks with large daily total volume into five quintiles based on $Z_{i, t}$. In Panel B, each day we sort the stocks in the largest size quartile and with large daily total volume into five quintiles based on $Z_{i, t}$. The first quintile, the second to fourth quintiles, and the fifth quintile are denoted by Low $Z_{i, t}$, Medium $Z_{i, t}$, and High $Z_{i, t}$, respectively. The first set of portfolios is based on foreign investors, and the second set is based on mutual funds. A stock is classified as "large buy (sell)" if the daily buy (sell) turnover is higher than its 200-day moving average, otherwise, it is "small buy (sell)". For each portfolio, we first calculate its daily equally weighted return for day $t+1$, and then calculate and report its time-series average, $t$ statistics in parentheses are based on Newey-West standard errors with 10 lagged autocorrelations. The sample includes 1,049 stocks for which there are at least 750 daily observations and that were listed on the Taiwan Stock Exchange and the Gre Tai Securities Market. The sample period is from 2000/12/12 to 2007/3/30.

\begin{tabular}{|c|c|c|c|c|c|c|}
\hline & \multicolumn{3}{|c|}{ Based on mutual funds trading } & \multicolumn{3}{c|}{ Based on foreigners' trading } \\
\hline $\begin{array}{c}\text { Net } \\
\text { margin trading }\end{array}$ & $\begin{array}{c}\text { Large Buy \& } \\
R_{t}>0\end{array}$ & $\begin{array}{c}\text { Large Sell \& } \\
R_{t}<0\end{array}$ & Difference & $\begin{array}{c}\text { Large Buy \& } \\
R_{t}>0\end{array}$ & $\begin{array}{c}\text { Large Sell \& } \\
R_{t}<0\end{array}$ & Difference \\
\hline Low & 0.753 & 0.079 & $\mathbf{0 . 6 7 4} * * *$ & 0.692 & 0.099 & $\mathbf{0 . 5 9 3}^{* * *}$ \\
\hline Medium & 0.385 & -0.061 & $\mathbf{0 . 4 4 6 * * *}$ & 0.329 & -0.109 & $\mathbf{0 . 4 3 8}^{* * *}$ \\
\hline High & 0.468 & -0.412 & $\mathbf{0 . 8 8 0}$ & $0.28 *$ & -0.424 & $\mathbf{0 . 7 0 4}^{* * *}$ \\
\hline
\end{tabular}

